\title{
Nanomedicine concepts in the general medical curriculum: initiating a discussion
}

\author{
This article was published in the following Dove Press journal: \\ International Journal of Nanomedicine \\ 7 December 2015 \\ Number of times this article has been viewed
}

\author{
Aldrin E Sweeney \\ Center for Teaching \& Learning, \\ Ross University School of Medicine, \\ Roseau, Commonwealth of Dominica
}

\begin{abstract}
Various applications of nanoscale science to the field of medicine have resulted in the ongoing development of the subfield of nanomedicine. Within the past several years, there has been a concurrent proliferation of academic journals, textbooks, and other professional literature addressing fundamental basic science research and seminal clinical developments in nanomedicine. Additionally, there is now broad consensus among medical researchers and practitioners that along with personalized medicine and regenerative medicine, nanomedicine is likely to revolutionize our definitions of what constitutes human disease and its treatment. In light of these developments, incorporation of key nanomedicine concepts into the general medical curriculum ought to be considered. Here, I offer for consideration five key nanomedicine concepts, along with suggestions regarding the manner in which they might be incorporated effectively into the general medical curriculum. Related curricular issues and implications for medical education also are presented.
\end{abstract}

Keywords: medical education, basic science, teaching, learning, assessment, nanoscience curriculum, nanomedicine concepts

\section{The evolving nature of medicine as a profession}

The history of the development of medicine as a profession - from antiquity through to the end of the 20th century - provides many vivid examples that illustrate how the practice of medicine (and, correspondingly, of formal medical education for successive generations of medical practitioners) has evolved over time. Pertinent examples may be drawn from a range of historical periods and world cultures, such as the influence of the noted polymath, Imhotep, on the development of ancient Egyptian medicine; the systematic study of "natural" causes of human disease ascribed to Hippocrates, the "Father of Western Medicine"; the Canon of Medicine compiled by Avicenna during the Islamic Golden Age; and the remarkable development of anatomy and physiology as rigorously empirical scientific disciplines during the Renaissance period in Europe. ${ }^{1}$ Within the Western medical tradition, the years 1850-1913 may be denoted as the period that signified the "rise of science in medicine". ${ }^{2}$ Conceptually, this may be considered to have led directly to the statement in Abraham Flexner's seminal 1910 report, ${ }^{3}$ in which he argued unequivocally that as a "proper basis of medical education", the fundamental sciences (ie, physics, chemistry, biology) "furnish, indeed, the essential instrumental basis of medical education". ${ }^{3}$

As we approach the third decade of the 21 st century, it is in the spirit of Flexner's continuing influence on contemporary medical education to consider how the current general medical curriculum should be adapted to incorporate scientific advances that will influence the nature and conduct of future professional medical practice. Over the past 25 years or so - since approximately 1990 - such advances have been occurring
Correspondence: Aldrin E Sweeney Center for Teaching \& Learning, Ross University School of Medicine, PO Box 266, Roseau, Commonwealth of Dominica

Email aldrinsweeney@rossu.edu submit your manuscript | www.dovepress.com

Dovepress

http://dx.doi.org//0.2147/IJN.S96480 
explicitly in the field of nanoscale science and technology. ${ }^{4}$ Pertinent to the diagnosis, screening, and therapeutic treatment of human diseases, these specific applications of various nanoscale technologies collectively are referred to as "nanomedicine", 5,6 "an emerging field that has the potential to revolutionize individual and population-based health in the 21 st century". ${ }^{7}$

It justifiably may be argued that nanomedicine is not yet a "fully mature" and established discipline. ${ }^{8,9}$ However, the field now is of sufficient maturity (ie, in terms of public and private funding for basic scientific research and development; numerous international professional organizations and conferences; increasing publications in the professional medical and scientific literature; and burgeoning numbers of clinical applications and patient trials ${ }^{4,9-12}$ ) to warrant consideration being given to its incorporation into the medical education curriculum and into the repertoire of future medical professional practice.

\section{What is nanomedicine?}

Nanoscience, very broadly, may be defined as the study of materials and associated physical, chemical, biophysical, and biochemical phenomena on the scale of $\sim 1-100 \mathrm{~nm}$ (ie, $10^{-9} \mathrm{~m}$ ). While the particular size thresholds stated in this definition still remain the subject of vigorous scientific debate, ${ }^{13}$ the primary appeal of nanoscience (and resulting technological applications) is the potential to control and manipulate matter at the nanoscale. Accordingly, nanotechnology may be conceptualized as the intentional design, production, and applications of materials, structures, devices, and systems by controlling their size and shape in the nanoscale range. ${ }^{14}$ Since nanomaterials typically are comparable in scale to the molecular structures comprising biological systems and may be designed to have very specific properties and functions, nanotechnology therefore has the potential to be used in medical applications. ${ }^{4,10,11}$

In 2004, the European Science Foundation proposed the following definition of nanomedicine:

The field of nanomedicine is the science and technology of diagnosing, treating and preventing disease and traumatic injury, of relieving pain, and of preserving and improving human health, using molecular tools and molecular knowledge of the human body. ${ }^{15}$

While this definition is comprehensive and has become influential in the field, it does not differentiate itself adequately from molecular medicine, which is based on a more conventional biochemical approach. ${ }^{6}$ In order to properly understand ongoing developments in nanomedicine, one needs to appreciate that the therapeutic properties of nanoscale materials purposely designed for use in medical contexts are, by definition, functions of their specific size and scale. Hence, a critical distinction between nanomedicine and other medical research fields (eg, molecular medicine) "is a focus on significantly changed medically related events that result by concentrating solely on the nanoscale". ${ }^{16}$

Two widely used drugs in clinical cancer therapy (ie, Doxil ${ }^{\circledR}$ and Abraxane ${ }^{\circledR}$ ) are examples of nanomedicines that have been designed for cancer chemotherapy, and which function in this capacity as a direct consequence of their physicochemical behavior at the nanoscale. ${ }^{17,18}$ Both are examples of what are known as "first generation" nanocarrier-based drug delivery systems, where tumors passively are targeted as a consequence of the enhanced permeation and retention effect. ${ }^{19-21}$ In addition to first-generation systems, "second generation" and "third generation" nanocarrier-based drug delivery systems (designed to accomplish more deliberate, active targeting of cancerous cells) continue to be developed for clinical use. ${ }^{4,11,12,18,22-27}$ While the preponderance of current research and clinical applications in nanomedicine is in the area of oncology and enhanced therapies for malignant solid tumors, ${ }^{25-30}$ a range of other efforts also are ongoing. These include, for example, investigational and commercially available nanomedicines for various infectious diseases, cardiac/vascular disorders, endocrine/exocrine disorders, and degenerative disorders; ${ }^{12}$ sustained drug release in the treatment of glaucoma; ;,31 and assessments of "pressing clinical needs amenable to nano-enabled technology" such as intelligent nanobiomaterials for cell therapy to improve heart function, cochlear and retinal implants, skin regeneration, and antimicrobials. ${ }^{4}$

In the USA, public funding for nanomedicine research falls under the aegis of federal funding allocated to the National Nanotechnology Initiative. ${ }^{32}$ At time of writing, for fiscal year 2016, the funding request for nanotechnology research and development (distributed across 20 participating federal agencies) currently stands at $\$ 1.5$ billion. It may be noted that of all participating federal agencies, the National Institutes of Health (NIH)

\section{[...] has the largest request among all agencies in FY 2016 [\$423 \\ million], to address nanotechnology-based biomedical research at the intersection of the life and physical sciences. ${ }^{32}$}

This indicates a significant investment in nanomedicine research, as broadly defined. However, some perspective may be gained by considering, for example, the NIH estimated fiscal year 2016 budget of just over $\$ 1$ billion ( $\$ 1,039$ million) for diabetes research alone. ${ }^{33}$ 
As indicated above, the majority of currently registered nanomedicine clinical trials focus primarily on therapeutic approaches for malignant solid tumors. Using data obtained from the ClinicalTrials.gov database, Table 1 provides ten examples that have been selected to indicate the range of medical conditions for which various nanotherapeutic and/or nanodiagnostic approaches currently are being employed in clinical trials.

Ultimately, the goal of nanomedicine research and development, followed by appropriately rigorous clinical trial protocols, is to successfully employ nanodiagnostic and nanotherapeutic applications in patient care, ie, completion of the "bench to bedside" cycle. Several clinically approved nanomedicines and nanoformulations have made the transition from bench to bedside, ${ }^{34}$ including, for example, Verigene $^{\circledR}$, a nanodiagnostic platform for the rapid identification of a range of infectious pathogens. ${ }^{35-38}$ In Europe, numerous examples may be noted of commercially available nanotherapeutic products for oral and parenteral administration, respectively. ${ }^{39}$

\section{Why is there a need for education and training in nanomedicine for future doctors?}

In a talk given at Southwestern University's Brown Symposium in 2014, noted nanomedicine researcher Dr Mauro Ferrari opined that "Between $5 \%-10 \%$ of all cancer drugs [in use today] are nanodrugs. Less than $5 \%-10 \%$ of cancer

Table I Selected examples of current registered clinical trials featuring nanotherapeutic/nanodiagnostic applications

\begin{tabular}{|c|c|c|c|}
\hline Study & Conditions & $\begin{array}{l}\text { Nanotherapeutic/nanodiagnostic } \\
\text { intervention(s) }\end{array}$ & $\begin{array}{l}\text { ClinicalTrials.gov } \\
\text { identifier }\end{array}$ \\
\hline $\begin{array}{l}\text { Paclitaxel Albumin-Stabilized Nanoparticle } \\
\text { Formulation in Treating Older Patients } \\
\text { With Locally Advanced or Metastatic } \\
\text { Breast Cancer }\end{array}$ & $\begin{array}{l}\text { Male breast cancer; } \\
\text { recurrent breast cancer; } \\
\text { stage IV breast cancer; etc }\end{array}$ & $\begin{array}{l}\text { Paclitaxel albumin-stabilized } \\
\text { nanoparticle formulation }\end{array}$ & NCT0I463072 \\
\hline $\begin{array}{l}\text { Magnetic Nanoparticle Thermoablation- } \\
\text { Retention and Maintenance in the Prostate: } \\
\text { A Phase } 0 \text { Study in Men (MAGNABLATE I) }\end{array}$ & Prostate cancer & Magnetic nanoparticle injection & NCT02033447 \\
\hline $\begin{array}{l}\text { A Clinical Study: the Antibacterial Effect of } \\
\text { Insoluble Antibacterial Nanoparticles (IABN) } \\
\text { Incorporated in Dental Materials } \\
\text { for Root Canal Treatment }\end{array}$ & $\begin{array}{l}\text { Endodontic treatment; } \\
\text { irreversible pulpitis; } \\
\text { infected pulp; etc }\end{array}$ & Device: IABN & NCT0II 67985 \\
\hline $\begin{array}{l}\text { Curcumin as a Novel Treatment to Improve } \\
\text { Cognitive Dysfunction in Schizophrenia }\end{array}$ & $\begin{array}{l}\text { Schizophrenia; cognition; } \\
\text { psychosis }\end{array}$ & $\begin{array}{l}\text { Theracurmin formulation of } \\
\text { curcumin nanoparticles }\end{array}$ & NCT02104752 \\
\hline $\begin{array}{l}\text { Nanoparticulate Versus Micronized Steroids } \\
\text { Delivery for Transdermal Hormone } \\
\text { Replacement Therapy (Nanoparticle) }\end{array}$ & Menopausal syndrome & $\begin{array}{l}\text { Drug: micronized estradiol + } \\
\text { progesterone } \\
\text { Drug: nanoparticulate estradiol + } \\
\text { progesterone }\end{array}$ & NCT02467673 \\
\hline $\begin{array}{l}\text { IRon Nanoparticle Enhanced MRI in the } \\
\text { Assessment of Myocardial infarctioN } \\
\text { (IRNMAN) }\end{array}$ & $\begin{array}{l}\text { Myocardial infarction; } \\
\text { inflammation }\end{array}$ & Device: ferumoxytol-enhanced MRI & NCT0I995799 \\
\hline $\begin{array}{l}\text { Investigation of Vascular Inflammation in } \\
\text { Migraine Using Molecular Nano-imaging and } \\
\text { Black Blood Imaging MRI }\end{array}$ & $\begin{array}{l}\text { Migraine headache; } \\
\text { migraine without aura }\end{array}$ & $\begin{array}{l}\text { Drug: Feraheme } \\
\text { Drug: cilostazol } \\
\text { Other: USPIO MRI } \\
\text { Other: BBI MRI }\end{array}$ & NCT02549898 \\
\hline $\begin{array}{l}\text { Evaluation of Nano-crystalline Hydroxyapatite } \\
\text { Silica Gel in Management of Periodontal } \\
\text { Intrabony Defects }\end{array}$ & Chronic periodontitis & $\begin{array}{l}\text { Biological: nanocrystalline } \\
\text { hydroxyapatite silica gel } \\
\text { Biological: bone allograft } \\
\text { Procedure: open flap debridement }\end{array}$ & NCT02507596 \\
\hline $\begin{array}{l}\text { Imaging Kidney Transplant Rejection Using } \\
\text { Ferumoxytol-Enhanced Magnetic Resonance }\end{array}$ & Renal transplant rejection & $\begin{array}{l}\text { Drug: Feraheme } \\
\text { Other: MRI-GE Healthcare } 3 \text { Tesla } \\
\text { magnet }\end{array}$ & NCT02006I08 \\
\hline $\begin{array}{l}\text { A Study of BIND-0I4 in Patients With } \\
\text { Urothelial Carcinoma, Cholangiocarcinoma, } \\
\text { Cervical Cancer and Squamous Cell } \\
\text { Carcinoma of the Head and Neck (iNSITE2) }\end{array}$ & $\begin{array}{l}\text { Urothelial carcinoma; } \\
\text { cholangiocarcinoma; } \\
\text { cervical cancer; squamous } \\
\text { cell carcinoma of head } \\
\text { and neck }\end{array}$ & $\begin{array}{l}\text { Drug: BIND-0I4 (docetaxel } \\
\text { nanoparticles for injectable } \\
\text { suspension) }\end{array}$ & NCT02479I78 \\
\hline
\end{tabular}

Notes: Data retrieved and compiled from the ClinicalTrials.gov website in October 2015 using the search term "nanoparticles", including only studies actively recruiting for clinical study participants and excluding studies with "unknown status".

Abbreviations: $\mathrm{BBI}$, black blood imaging; MRI, magnetic resonance imaging; USPIO, ultrasmall superparamagnetic iron oxide contrast agent. 
doctors know that". 40 This view is supported by Moore, who (within the context of medical education in the UK where a "foundation programme" broadly is analogous to an "internship" or "residency" program in the USA), warned that:

Currently, nanomedicine rarely features in mainstream medical training or in continuing professional development.

[...] Yet, by the time the current intake of medical students graduate as doctors and subsequently complete their two-year foundation programme, many new nanomedical products are likely to be appearing. ${ }^{41}$

Both comments underscore the fact that contemporary medicine is becoming increasingly dynamic, with the expectation that rapid advances in nanomedicine research and associated technologies ${ }^{42,43}$ are likely to profoundly impact the conduct of future medical practice. Given the pace with which such developments are occurring, the comparative lack of familiarity held by many current and prospective doctors with regard to nanomedicine suggests an increasingly urgent need for education and training in this field. While the ensuing commentary encompasses the necessity of continuing professional development activities in nanomedicine for current medical professionals, primary focus is given here to the medical education of future doctors.

\section{Tomorrow's Doctors and Scientific Foundations for Future Physicians}

In recent years, two influential publications have addressed the need for widespread reform in medical education (including the structure, purposes, and goals of the general medical curriculum) and the professional competencies that will be required for 21st-century doctors. Tomorrow's Doctors: Outcomes and Standards in Undergraduate Medical Education ${ }^{44}$ and Scientific Foundations for Future Physicians ${ }^{45}$ both provide comprehensive guidelines and recommendations for the medical education of future doctors within the continuously evolving landscape of professional medical practice. In particular, both publications emphasize the necessity of future doctors being able to demonstrate comprehensive knowledge and understanding of the basic sciences that will provide the foundation for their future professional careers. It also is noteworthy that both publications are remarkably consistent in advising that "today's undergraduates - tomorrow's doctors- will see huge changes in medical practice" as a consequence of "continuing developments in biomedical sciences and clinical practice", ${ }^{44}$ and that:
Concerns about the science content in the current premedical and medical education curricula [...] are especially important given the increasingly rapid rate at which new knowledge revises our understanding of the sciences fundamental to medicine. ${ }^{45}$

In light of these concerns, the following starkly worded statement becomes all the more troubling:

There is also widespread concern that the basic science content in the medical school curriculum has not kept pace with the expanding scientific knowledge base of medicine and fails to reflect accurately the importance of the sciences in the practice of medicine. ${ }^{45}$

Numerous examples may be found in the medical education literature of commentaries issuing similar warnings. ${ }^{46-51}$ While the commentaries offer a variety of sometimes competing perspectives (eg, in terms of the extent and depth of basic science content in the medical curriculum or the relative importance of the basic sciences compared to the development of clinical diagnostic skills in the professional education of doctors), there is general consensus that unprecedented advances in scientific knowledge and in contemporary medical practice necessitate corresponding adaptations in the general medical curriculum.

Neither Tomorrow's Doctors nor Scientific Foundations (both published in 2009) included any mention of the terms "nanoscience", "nanotechnology", or "nanomedicine". Given the fact that nanomedicine - in its contemporary sense - very much was a nascent field at the time, this is quite understandable. However, with the extent of nanomedicine research now occurring, and with the range of nanomedical applications being developed and tested in various stages of clinical trials, ${ }^{4-6,12,13,20,25-28,40-43}$ it would be unwise for future editions of these documents (or similar publications by other medical education bodies elsewhere) not to give this due attention. Since nanomedicine distinctly is beginning to influence the way in which we think about future medical therapies and professional practice, ${ }^{5}$ it now becomes incumbent on medical educators to begin giving consideration to the manner in which relevant principles and concepts might be incorporated into the general medical curriculum.

\section{Key nanomedicine concepts: suggestions for their incorporation into the general medical curriculum}

Moore ${ }^{41}$ has proposed that "a basic training module" in nanomedicine for mainstream medical education and ongoing 
professional development ideally ought to feature a number of topics, including terminology; fundamental scientific principles of physicochemical behavior at the nanoscale; applications of nanotechnology in medically relevant fields such as imaging, diagnostics, tissue engineering, and drug design; and applications of nanotechnology to various clinical disciplines (eg, oncology, cardiovascular medicine, neurology, orthopedics). This comprehensive listing of topics is of considerable merit, particularly in terms of articulating broad aspects of nanomedicine in which prospective and current medical doctors ought to be knowledgeable. However, the proposal of a "basic training module" in nanomedicine implies another body of curricular content that might be perceived as distinct and separate to the content already present. Taking into account the ongoing debate regarding the bloated medical curriculum ${ }^{47,48,52-57}$ in addition to recent calls for shorter, "fast tracked" 58 or accelerated medical programs ${ }^{59}$ a more practicable approach might be to incorporate key nanomedicine concepts appropriately into established "standard" content that already is being taught in the medical curriculum. Five key nanomedicine concepts are presented, with brief suggestions regarding the manner in which they might be incorporated into the existing general medical curriculum.

\section{Size and scale}

The particular physicochemical behavior of engineered materials and devices at a specific size and scale (ie, the nanoscale) is the primary concept underlying nanotechnology, including applications related to medical or therapeutic contexts. Surface effects and quantum mechanical effects, respectively, are the main factors that cause nanomaterials to behave very differently when compared to their bulk counterparts. ${ }^{60,61}$ At the nanoscale, the surface area-to-volume ratio of materials and devices increases dramatically, and as a result of this, chemical reactivity, mechanical properties, and catalytic properties typically become significantly enhanced at this scale.

Assuming that students already will have received some exposure to concepts of size and scale in middle/high school science and mathematics classes, introductory content about the behavior of materials and devices at the nanoscale ideally could be introduced in premedical course requirements, specifically in undergraduate-level general physics, chemistry, and biology courses, respectively. ${ }^{62-64}$ Consequently, by the time of admission into a medical program, medical students already would be familiar with the terms "nanoscale", "nanoscience", and "nanotechnology". Further discussion emphasizing conceptual understanding of size and scale could be continued and reinforced in the first year of a "standard" medical program, most likely within courses such as biochemistry, genetics, and microbiology, respectively. Here, students' attention could be directed explicitly to the fact that, in general, nanomaterials and associated nanoscale devices typically are comparable in size to viruses, DNA, proteins, subcellular organelles, and gap junctions. ${ }^{60,63}$ While it would not be necessary to discuss the more detailed aspects of, for example, quantum confinement effects, the principle of changed or enhanced physicochemical properties of engineered materials at the nanoscale could be taught as a key concept at this point.

\section{Interaction of nanomaterials with biological systems and design of nanomedicines}

As Buzea et al state in their excellent review, "every person has been exposed to nanometer-sized foreign particles; we inhale them with every breath, and consume them with every drink". ${ }^{60}$ These include viruses, as well as nanoparticles produced by a variety of natural processes and human activities. ${ }^{60}$ In terms of nanomaterials and nanoscale devices designed specifically for use in medical contexts, primary methods of administration include oral, dermal, pulmonary, ocular, and parenteral routes, with the majority of nanomedicines currently in use formulated for parenteral (intravenous) administration. ${ }^{65,66}$ However, upon entering the bloodstream, binding of blood proteins to the surface of injected nanomaterials occurs as part of the body's immune response. Subsequent opsonization and uptake by the mononuclear phagocyte system promotes removal of the administered nanomedicine from the bloodstream, thus hindering its bioavailability and intended therapeutic purpose. ${ }^{65,67-69}$ In an attempt to "evade" the body's immune response, several techniques have been developed in order to prevent or reduce this protein binding as much as possible. Typically, these techniques involve modification of the surface properties of nanomedicines with various polymers (eg, polyethylene glycol) that prevent opsonization and phagocyte clearance. ${ }^{65,70-73}$ In addition to issues regarding biocompatibility and biodegradability, ongoing research addressing the interaction of nanomaterials with biological systems and the design of nanomedicines also continues to explore potential toxicological concerns..$^{65,73-75}$

Within the standard medical curriculum, topics relating to protein binding, cell signaling, immunological responses, and pharmacodynamics/pharmacokinetics are taught in 
microbiology, biochemistry, immunology, and pharmacology courses, respectively. It is likely that examples relating to the interaction of nanomaterials with biological systems and the subsequent design of nanomedicines could be incorporated fairly readily into this existing curricular structure.

\section{Mechanisms of drug delivery}

As mentioned previously, most nanomedicine research efforts to date have focused on developing therapies for malignant solid tumors. ${ }^{21,76-78}$ Mechanisms for delivery of therapeutic nanomaterials to cancerous tissue occur via passive or active nanomedicine drug targeting. Passive targeting occurs as the result of spontaneous drug accumulation in cancerous sites with typically leaky vasculature, leading to the enhanced permeation and retention effect. ${ }^{79}$ Active targeting methods exploit the fact that, at the cellular level, many pathological states may be identified by a display of surface proteins that are absent in healthy cells, or which are overexpressed in comparison to healthy cells. Surface functionalization of nanomedicines with ligands that bind selectively to proteins expressed on the surface of unhealthy tissue allows specific targeting of the nanomedicine to the diseased site ${ }^{80}$ Ongoing research efforts continue to explore more sophisticated and precise active targeting approaches for cancer therapy. ${ }^{65}$ In addition to cancer therapy, efforts to develop selective nanomedicine targeting also are being extended into antiviral drug delivery ${ }^{81}$ and to pathologies affecting the central nervous system (eg, Alzheimer's disease, Parkinson's disease). ${ }^{82-85}$

Within the standard medical curriculum, principles related to passive and active nanomedicine drug targeting readily could be accommodated within microbiology, biochemistry, pharmacology, and pathology courses, respectively. Given the particular difficulty of targeted drug delivery across the blood-brain barrier, this also may be emphasized in the physiology course component of the existing medical curriculum.

\section{Nanodiagnostics}

The use of nanotechnology for clinical diagnostic purposes has developed in response to the demands of clinical diagnostics for increased sensitivity and earlier detection of disease. The central principle describing the mechanism of nanoparticle-based assays is the selective binding of a nanoparticle label or probe to a target biomolecule (eg, DNA, RNA, peptides, antigens, or other small analytes) that typically also will have nanometer-scale dimensions. As a consequence of binding to the target molecule, a measurable signal - characteristic of the target biomolecule - is produced. ${ }^{86-88}$ Due to the sensitivity with which such target biomolecules (or "biomarkers") may be measured by nanoparticle-based assays, ${ }^{89}$ "nanodiagnostic devices are expected to eventually supplant diagnostic tools that aren't as sensitive, convenient, efficient, or cost-effective". ${ }^{20}$ Sensitivity limitations of current diagnostic tools result in the detection of some diseases only at an advanced stage: for example, current methods of cancer diagnosis rely on "bulk" measurement assays of surface proteins expressed on the surface of malignant cancerous cells or the detection of a solid tumor that already will contain millions of cancerous cells. ${ }^{20}$ Using a number of in vitro and in vivo methods, ${ }^{89}$ nanodiagnostic devices are able to detect the presence of relevant biomarkers (eg, surface proteins of cancerous cells or circulating tumor DNA) at much lower levels, and potentially are able to measure the presence of target biomarkers at the level of single cells and molecules. ${ }^{68,90} \mathrm{In}$ addition to point-of-care nanodiagnostic methods that have been developed for a range of cancers, ${ }^{91,92}$ point-of-care nanodiagnostics continue to be developed for several other pathologies, including Alzheimer's disease, ${ }^{20,93}$ diabetes, ${ }^{94,95}$ and a number of viral and bacterial infections. ${ }^{96-98}$

Key principles describing nanoparticle-based assays might be incorporated into a premedical-level introduction to medicine course (including diagnosis and patient care), or perhaps into an introduction to clinical medicine course in the general medical curriculum. Within the basic sciences component of the current general medical curriculum, curricular logistics might make it more challenging to incorporate these principles into a traditional biochemistry or pathology course, since they might be perceived as belonging more in the domain of a clinical sciences or medical laboratory sciences degree program. However, the underlying basic science concepts certainly are applicable and may be taught within the contexts of traditional biochemistry and/or pathology courses (ie, targeted recognition by nanoparticle labels of biomarkers expressed at the cellular/tissue level in various pathologies), and the topic of nanodiagnostics may be reinforced explicitly in the clinical experiences component of the general medical degree program.

\section{Potential ethical issues}

The increasing use of nanodiagnostics and nanotherapeutics in identifying and treating a range of human pathologies 
raises several ethical conundrums. As one example, if the sensitivity of diagnostic nanotechnologies becomes such that likely malignant cancers may be identified at the level of single cells, then "how many cells from the body must be of a cancerous nature for it to be defined as cancer?" 99 How might such a scenario lead physicians to reconceptualize how human "disease" is defined, along with appropriate medical interventions? ${ }^{99}$ In addition to general commentaries addressing social and ethical dimensions of nanoscale science and engineering research, ${ }^{100,101}$ a growing body of professional literature continues to address potential ethical issues arising specifically from the use of various nanotechnologies in clinical diagnosis and medical treatment. Key issues include the observation that "nanomedicine is likely to be one of the most - if not the most-profitable applications of nanotechnology", ${ }^{102}$ and as other commentators have noted, such "extreme profitability" 102 leads to concerns that global equality in access to health care might be even further compromised. ${ }^{103,104}$ Rather notably, in 2012, the Journal of Law, Medicine \& Ethics published a special issue that featured a number of perspectives from research scientists, bioethicists, and others ${ }^{105-111}$ addressing potential ethical issues in nanomedicine. While there are concerns that "nanomedical interventions present a higher level of uncertainty than do more conventional biomedical interventions" 107 - particularly with regard to clinical trials of nanomedicines in humans - most commentators agree that, fundamentally, there are no "new" ethical concerns specific to medical nanotechnologies ${ }^{102,105,112}$ that are not subsumed within existing biomedical ethics guidelines. ${ }^{113}$ However, there appears to be broad consensus that the potential scope, extent, and technical complexities of medical nanotechnologies justify further, long-term examination of potential ethical implications. ${ }^{107,108,114}$

Within the existing general medical curriculum, issues pertaining to potential ethical concerns in nanomedicine may be accommodated in a standard professional medical ethics class that utilizes, for example, Beauchamp and Childress' widely cited four principles of biomedical ethics, ie, respect for autonomy, beneficence, non-maleficence, and justice. ${ }^{113}$ Given the critical importance of developing effective skills in doctor-patient communication ${ }^{115,116}$ and the practical inseparability of communication skills and ethical behaviors, ${ }^{117}$ it also is likely that potential ethical concerns in nanomedicine could be addressed in a number of professional communication and clinical skills courses offered in various general medical curricula.

\section{Anticipated curricular challenges}

No attempt is made here to be prescriptive regarding appropriate points at which these five suggested concepts ought to be introduced and taught in the general medical curriculum, nor is it implied that these concepts are exhaustive. Such considerations remain open to debate and rebuttal. Clearly, the concepts listed above are not discrete, and considerable overlap exists between them. They are presented here as a potential guide in terms of how they effectively might be incorporated in a systematic and coherent manner into the existing medical curriculum. At least three significant "curricular challenges" to these suggestions may be anticipated, and these are outlined briefly below.

\section{Excessive basic science content in the general medical curriculum}

The ongoing debate concerning "too much" basic science content in the general medical curriculum has been amply documented. ${ }^{46-57}$ This is likely to be one of the primary objections against incorporating key nanomedicine concepts into what long has been argued is an already "overstuffed curriculum". ${ }^{118}$ Nevertheless, if there is broad agreement within the medical education community that existing basic science content in the general medical curriculum does not adequately address "the expanding scientific knowledge base of medicine" ${ }^{45}$ it then becomes necessary to consider the ways in which "medical school curricula must continue to adapt in order to best prepare physicians for practice in the twenty-first century". ${ }^{49}$ In practical terms, it must be acknowledged that a rapidly increasing basic science knowledge base - together with additional professional medical competencies - physically cannot be accommodated within the existing structure of the general medical curriculum. However, as cogently argued by Brass:

The wrong solution is to reduce traditional necessary core material to accommodate new core material. The debate is what is necessary, $[\ldots]$, and what broader restructuring may be required to accommodate the new educational requirements. ${ }^{48}$

Currently, two curricular formats appear to be the primary avenues through which a comparatively small number of prospective medical doctors are exposed to various nanomedicine concepts. First is the $\mathrm{MD} / \mathrm{PhD}$ program format, in which the express goal of the typically 7- to 8-year program is to produce a new "hybrid" generation of research 
physicians who are skilled in the scientific development and clinical use of various medical nanotechnologies. ${ }^{19,120}$ Second is the scholarly concentrations format (occurring during the standard timeline of the regular general medical program), in which students undertake guided independent research projects that address some aspect of the application of nanotechnologies to medical practice. ${ }^{121,122}$ Although these approaches - or variations thereof - have received support in the medical education community, ${ }^{7,52,123}$ it may be argued that neither one satisfactorily resolves the issue of "how broadly [all prospective physicians] in the 21 st century should be exposed to the scope of the biological sciences". ${ }^{124}$ The approaches as described represent excellent career-enhancing opportunities for medical students who wish to undertake laboratory research and become clinician-scientists: however, exposure to key "nanomedicine concepts" cannot remain exclusively in the domain of $\mathrm{MD} / \mathrm{PhD}$ programs or scholarly concentrations alone if all future physicians are to have some knowledge and competence in nanomedicine.

\section{Basic science vs clinical science components of the general medical curriculum}

In addition to differences of professional opinion concerning "too much" basic science in the general medical curriculum, a related curricular debate addresses what typically is perceived to be the poorly articulated nature of the basic science and clinical science components, respectively. Efforts to establish truly integrated medical curricula continue to be undertaken with varying degrees of success. ${ }^{49,50,125,126}$ The issue further is compounded by students who often do not clearly understand the relevance of their basic science classes to clinical care, and by encounters with clinical faculty who do not adequately model the role of basic science knowledge in clinical decision-making. ${ }^{48}$ As proposed above, applicable concepts in nanomedicine should be incorporated comprehensively across the medical curriculum, during both preclinical and clinical stages. Since the physicochemical principles of how nanomaterials interact with biological systems are linked intimately (both conceptually and procedurally) to nanotechnology-enabled diagnostics and therapeutic approaches, it may be argued that nanomedicine is likely to ameliorate rather than exacerbate a perceived discontinuity between basic science and clinical applications. The current growth of "nanotheranostics" (ie, the simultaneous integration of nanotechnology-enabled diagnosis and therapy) $)^{127,128}$ also may serve an important role in making the "disconnect" between basic science and clinical medicine conceptually obsolete.

\section{Testing and assessment}

It is well known at all educational levels that assessment drives instruction. Equally significant is the aphorism that "what examinations ask determines what students learn". ${ }^{118}$ Within the context of medical schools in the USA (and a number of medical schools in Canada), the Medical College Admissions Test ${ }^{\circledR}$ (MCAT) typically is used as a measure of students' academic preparedness and ability to successfully undertake a medical program of study. ${ }^{129}$ However, both premedical courses and the MCAT have been criticized on the basis that they do not adequately take into account advances in scientific knowledge at the cellular and molecular levels that will be required for the practice of medicine in the 21 st century. ${ }^{47,51}$ Similar critiques may be made of the United States Medical Licensing Examination (USMLE), which also has been claimed to encourage the "binge and purge" mentality of students who do not recognize the importance of the basic sciences in medical practice, and hence tend to memorize basic science information for short-term retention only. ${ }^{51,130-133}$ At time of writing, several significant changes have occurred to the format of both the MCAT and the USMLE. In an effort to "focus on skills and concepts that tomorrow's doctors will need", it may be noted that the updated version of the MCAT (April 2015) now tests

$[\ldots]$ cellular and molecular biology topics $[\ldots]$ and biochemistry concepts at the level taught in many colleges and universities in first-semester biochemistry courses $[\ldots] \cdot{ }^{134}$

in addition to practical applications of biotechnology "which directly impact humans, such as medical applications, human gene therapy, and pharmaceuticals". ${ }^{134}$ Such developments are likely to augur well for the eventual introduction of interdisciplinary nanoscience concepts into premedical and basic medical sciences curricula. Concurrent changes in the USMLE include:

Increased numbers of items that assess an expanded range of competency-based content, including foundational science essential for effective healthcare. ${ }^{135}$

Of particular significance is the narrative included in the current Content Description and General Information guidelines for both USMLE Step 1 and Step 2 (clinical knowledge), which indicates that: 
The content outline is not intended as a curriculum development or study guide. It provides a flexible structure for test construction that can readily accommodate new topics, emerging content domains, and shifts in emphasis. The categorizations and content coverage are subject to change. ${ }^{136}$

While it might not be the intent for these content outlines to serve as curriculum development or study guides, it may be argued that any articulation of content knowledge to be tested or assessed automatically will influence curricular development and instructional priorities. Given the implicit acknowledgment that the USMLE will continue its adaptation to accommodate new topics and emerging content domains, ${ }^{136,137}$ it will be of great interest over the next several years to note the extent to which testing and assessment of applicable nanomedicine concepts are incorporated into this pivotal high-stakes examination.

\section{Concluding comments}

Fundamental to the discussion presented here is the unavoidable realization that contemporary medical education must continue to adapt if it is to adequately prepare physicians to practice medicine in the 21 st century. As proposed in this article, an important aspect of this adaptation necessarily will include the incorporation of key nanomedicine concepts into the general medical curriculum. It is not my intent here to offer unfounded prognostications on the future of professional medical education and practice: nevertheless, it is difficult not to agree with Kanter, who has argued that the incipient generation of medical doctors and research scientists:

[...] will administer to patients treatments that have not yet been discovered based on heretofore inaccessible understandings and classifications of disease, in a health care environment that surely will undergo significant change. ${ }^{138}$

How we address these significant changes will need to be tempered with careful deliberation and considerable professional judgment. Due to the accuracy, sensitivity, and sophistication of nanotechnology-enabled diagnostic methods, future definitions of what constitute human "health" and human "disease" will need to be reconsidered. How will future doctors diagnose and provide medical treatment to patients who do not necessarily exhibit any overt, observable clinical signs? How will clinical or pathological relevance be determined? ${ }^{99}$ In concert with "organ-on-a-chip" and "human-on-a-chip" technologies for drug research and discovery, ${ }^{139}$ how might nanodiagnostic methods revolutionize our concepts of "clinical medicine" and the manner in which clinical knowledge, clinical reasoning, and clinical skills are taught and assessed? Will physicians' development of relevant illness scripts ${ }^{140-143}$ undergo modification, and if so, to what extent?

For the time being, these are presented as rhetorical (and perhaps provocative) questions intended to stimulate discussion and debate. More immediate concerns relate to the impact on the present structure of the general medical curriculum and the restructuring that will need to occur in educational preparation and academic requirements for future students seeking to undertake a medical program of study. As Cavazos has indicated,

Medical schools are particularly good at imparting the skills of the profession to their students, but much else that goes into the making of a physician is acquired long before medical school. ${ }^{144}$

If nanomedicine truly is to revolutionize the way in which medicine as a profession will be practiced, perhaps now is an appropriate juncture at which the medical education community reevaluates its philosophy of premedical education ${ }^{124,145}$ and its involvement in the premedical liberal arts and science curriculum to better address current advances in biomedical sciences, medical nanotechnologies, and public health policy. Similar to focused efforts that have occurred to incorporate nanoscale science concepts into undergraduate science and engineering programs (in addition to high school science curricula), ${ }^{14,146}$ corresponding efforts also should be initiated for premedical education and general medical programs of study. More broadly, perhaps now is a particularly opportune time at which to consider the evolution of medical education into a more thoroughly interdisciplinary, integrated teaching and research endeavor. ${ }^{147}$

The process of adapting to continued advances in scientific knowledge is an important, and often, a highly challenging task. ${ }^{148,149}$ No less challenging will be the task faced by the medical education community to comprehensively address the issues and implications presented here for discussion.

\section{Acknowledgments}

The author gratefully acknowledges Shommari Waseme for engaging in several critical discussions that contributed to the conceptualization of this article. The author also wishes to thank Kadeen Cooke and Christine M Victor for their encouragement and support during the preparation of this 
article. Special thanks are extended to Nadia Poponne for her invaluable assistance in locating several key references for my review. The professional views expressed herein are those of the author alone and do not imply endorsement by Ross University School of Medicine nor any of its institutional affiliates.

\section{Disclosure}

The author reports no conflicts of interest in this work.

\section{References}

1. Osler W. The Evolution of Modern Medicine: A Series of Lectures Delivered at Yale University on the Silliman Foundation in April, 1913. New Haven: Yale University Press; 1921.

2. Bynum WF, Hardy A, Jacyna S, Lawrence C, Tansey EM. The Western Medical Tradition: 1800 to 2000. New York: Cambridge University Press; 2006.

3. Flexner A. Medical Education in the United States and Canada: A Report to the Carnegie Foundation for the Advancement of Teaching. Boston: D. B. Updike, The Merrymount Press; 1910.

4. Murday JS, Siegel RW, Stein J, Wright JF. Translational nanomedicine: status assessment and opportunities. Nanomedicine. 2009;5:251-273.

5. Morrow KJ Jr, Bawa R, Wei C. Recent advances in basic and clinical nanomedicine. Med Clin North Am. 2007;91:805-843.

6. Riehemann K, Schneider SW, Luger TA, Godin B, Ferrari M, Fuchs H. Nanomedicine - challenge and perspectives. Angew Chem Int Ed Engl. 2009;48:872-897.

7. Pautler M, Brenner S. Nanomedicine: promises and challenges for the future of public health. Int J Nanomedicine. 2010;5:803-809.

8. Wong KK, Liu XL. Nanomedicine: a primer for surgeons. Pediatr Surg Int. 2012;28:943-951.

9. Venkatraman S. Has nanomedicine lived up to its promise? Nanotechnology. 2014;25:372501.

10. Kim BY, Rutka JT, Chan WC. Nanomedicine. $N$ Engl J Med. 2010;363:2434-2443.

11. Liu Y, Miyoshi H, Nakamura M. Nanomedicine for drug delivery and imaging: a promising avenue for cancer therapy and diagnosis using targeted functional nanoparticles. Int $J$ Cancer. 2007;120: 2527-2537.

12. Etheridge ML, Campbell SA, Erdman AG, Haynes CL, Wolf SM, McCullough J. The big picture on nanomedicine: the state of investigational and approved nanomedicine products. Nanomedicine. 2013;9:1-14.

13. Duncan R, Gaspar R. Nanomedicine(s) under the microscope. Mol Pharm. 2011;8:2101-2141.

14. Sweeney AE, Seal S, editors. Nanoscale Science and Engineering Education. Los Angeles: American Scientific Publishers; 2008

15. European Science Foundation (ESF). Nanomedicine: An ESF-European Medical Research Councils (EMRC) Forward Look Report. Strasbourg: ESF; 2005. Available from: http://www.esf.org/fileadmin/ Public_documents/Publications/Nanomedicine.pdf. Accessed November 25, 2015.

16. Webster TJ. Nanomedicine: what's in a definition? Int J Nanomedicine. 2006;1:115-116.

17. Green AE, Rose PG. Pegylated liposomal doxorubicin in ovarian cancer. Int J Nanomedicine. 2006;1:229-239.

18. Miele E, Spinelli GP, Miele E, Tomao F, Tomao S. Albumin-bound formulation of paclitaxel (Abraxane ABI-007) in the treatment of breast cancer. Int J Nanomedicine. 2009;4:99-105.

19. Serda RE, Godin B, Blanco E, Chiappini C, Ferrari M. Multi-stage delivery nano-particle systems for therapeutic applications. Biochim Biophys Acta. 2011;1810:317-329.

20. Ventola CL. The nanomedicine revolution: part 2: current and future clinical applications. $P$ T. 2012;37:582-591.
21. Bertrand N, Wu J, Xu X, Kamaly N, Farokhzad OC. Cancer nanotechnology: the impact of passive and active targeting in the era of modern cancer biology. Adv Drug Deliv Rev. 2014;66:2-25.

22. Tasciotti E, Liu X, Bhavane R, et al. Mesoporous silicon particles as a multistage delivery system for imaging and therapeutic applications. Nat Nanotechnol. 2008;3:151-157.

23. Bourzac K. Nanotechnology: carrying drugs. Nature. 2012;491: S58-S60.

24. Martinez JO, Brown BS, Quattrocchi N, Evangelopoulos M, Ferrari M, Tasciotti E. Multifunctional to multistage delivery systems: the evolution of nanoparticles for biomedical applications. Chin Sci Bull. 2012;57:3961-3971.

25. Akhter S, Ahmad I, Ahmad MZ, et al. Nanomedicines as cancer therapeutics: current status. Curr Cancer Drug Targets. 2013;13:362-378.

26. Wang R, Billone PS, Mullett WM. Nanomedicine in action: an overview of cancer nanomedicine on the market and in clinical trials. $J$ Nanomater. 2013;2013:629681.

27. Pillai G. Nanomedicines for cancer therapy: an update of FDA approved and those under various stages of development. SOJ Pharm Pharm Sci. 2014;1:13.

28. Rizzo LY, Theek B, Storm G, Kiessling F, Lammers T. Recent progress in nanomedicine: therapeutic, diagnostic and theranostic applications. Curr Opin Biotechnol. 2013;24:1159-1166.

29. Conde J, Oliva N, Artzi N. Implantable hydrogel embedded dark-gold nanoswitch as a theranostic probe to sense and overcome cancer multidrug resistance. Proc Natl Acad Sci U S A. 2015;112:E1278-E1287.

30. Markman JL, Rekechenetskiy A, Holler E, Ljubimova JY. Nanomedicine therapeutic approaches to overcome cancer drug resistance. Adv Drug Deliv Rev. 2013;65:1866-1879.

31. Natarajan JV, Darwitan A, Barathi VA, et al. Sustained drug release in nanomedicine: a long-acting nanocarrier-based formulation for glaucoma. ACS Nano. 2014;8:419-429.

32. Roco MC. National Nanotechnology Investment in the FY 2016 Budget [webpage on the Internet]. Washington: American Association for the Advancement of Science; 2015. Available from: http://www.aaas. org/fy16budget/national-nanotechnology-investment-fy-2016-budget. Accessed October 30, 2015.

33. Estimates of Funding for Various Research, Condition, and Disease Categories (RCDC) [webpage on the Internet]. Washington: U.S. Department of Health \& Human Services; 2015 [updated July 8, 2015]. Available from: http://report.nih.gov/categorical_spending.aspx. Accessed October 30, 2015.

34. Clinically approved nanomedicines and nanoformulations [webpage on the Internet]. Liverpool: British Society for Nanomedicine. Available from: http://www.britishsocietynanomedicine.org/ existing-nanomedicines.html. Accessed November 3, 2015.

35. Verigene System [webpage on the Internet]. Northbrook: Nanosphere, Inc. Available from: http://www.nanosphere.us/products/verigenesystem. Accessed November 3, 2015.

36. Wojewoda CM, Sercia S, Navas S, et al. Evaluation of the Verigene Gram-positive blood culture nucleic acid test for rapid detection of bacteria and resistance determinants. J Clin Microbiol. 2013;51:2072-2076.

37. Beal SG, Ciurca J, Smith G, et al. Evaluation of the nanosphere Verigene gram-positive blood culture assay with the VersaTREK blood culture system and assessment of possible impact on selected patients. J Clin Microbiol. 2013;51:3988-3992.

38. Dodémont M, De Mendonça R, Nonhoff C, Roisin S, Denis O. Performance of the Verigene Gram-negative blood culture assay for rapid detection of bacteria and resistance determinants. $J$ Clin Microbiol. 2014;52:3085-3087.

39. Hafner A, Lovrić J, Lakoš GP, Pepić I. Nanotherapeutics in the EU: an overview on the current state and future directions. Int J Nanomedicine. 2014;9:1005-1023.

40. Ferrari M. Brown Symposium XXXVI-Mauro Ferrari: "Nanomedicine and New Societal Horizons". YouTube; 2014. Available from: https:// www.youtube.com/watch?v=4p2tnkMy1bs. Accessed May 1, 2015.

41. Moore R. Nanomedicine: rethinking medical training. Med Device Technol. 2008;19:50, 52-53. 
42. Moore R. Nanoscience and future trends in medical technologies. European Medical Device Technology. 2010;1(5). Available from: http://www.emdt.co.uk/article/nanoscience-and-future-trends-medicaltechnologies. Accessed May 10, 2015.

43. Moore R. Unlocking the potential of medical nanotechnology. European Medical Device Technology. 2013;4(2). Available from: http:// www.emdt.co.uk/article/unlocking-potential-medical-nanotechnology. Accessed May 10, 2015.

44. General Medical Council (GMC). Tomorrow's Doctors: Outcomes and Standards for Undergraduate Medical Education. Manchester: GMC; 2009.

45. AAMC-HHMI Committee. Scientific Foundations for Future Physicians. Washington: AAMC-HHMI Committee; 2009.

46. Norman G. The essential role of basic science in medical education: the perspective from psychology. Clin Invest Med. 2000;23:47-51.

47. Dienstag JL. Relevance and rigor in premedical education. $N$ Engl J Med. 2008;359:221-224.

48. Brass EP. Basic biomedical sciences and the future of medical education: implications for internal medicine. J Gen Intern Med. 2009;24:1251-1254.

49. Grande JP. Training of physicians for the twenty-first century: role of the basic sciences. Med Teach. 2009;31:802-806.

50. Finnerty EP, Chauvin S, Bonaminio G, Andrews M, Carroll RG, Pangaro LN. Flexner revisited: the role and value of the basic sciences in medical education. Acad Med. 2010;85:349-355.

51. Lambert DR, Lurie SJ, Lyness JM, Ward DS. Standardizing and personalizing science in medical education. Acad Med. 2010;85: 356-362.

52. Fincher RM, Wallach PM, Richardson WS. Basic science right, not basic science lite: medical education at a crossroad. J Gen Intern Med. 2009;24:1255-1258.

53. Moreland BH. How much biochemistry should a good doctor know? Biochem Educ. 1996;24:79.

54. Cohen RD. Features section: how much biochemistry should a medical student be taught? - The viewpoint of the General Medical Council. Biochem Educ. 1996;24:80-82.

55. Wood EJ. How much biochemistry should a good doctor know? A biochemist's viewpoint. Biochem Educ. 1996;24:82-85.

56. Dennick R. How much biochemistry should a good doctor know? An educationalist's perspective. Biochem Educ. 1996;24:85-88.

57. Saffran M. How much biochemistry should a good doctor know? Biochem Educ. 1997;25:129-133.

58. Abramson SB, Jacob D, Rosenfeld M, et al. A 3-year M.D. - accelerating careers, diminishing debt. N Engl J Med. 2013;369:1085-1087.

59. Goldfarb S, Morrison G. The 3-year medical school - change or shortchange? N Engl J Med. 2013;369:1087-1089.

60. Buzea C, Pacheco II, Robbie K. Nanomaterials and nanoparticles: sources and toxicity. Biointerphases. 2007;2:MR17-MR71.

61. Burgess R. Understanding Nanomedicine: An Introductory Textbook. Singapore: Pan Stanford Publishing Pte. Ltd; 2012.

62. Wolf EL. Nanophysics and Nanotechnology: An Introduction to Modern Concepts in Nanoscience. Weinheim: Wiley-VCH; 2004.

63. Whitesides GM. Nanoscience, nanotechnology, and chemistry. Small. 2005;1:172-179.

64. Hobbie RK, Roth BJ. Intermediate Physics for Medicine and Biology. 4th ed. New York: Springer Science + Business Media, LLC; 2007.

65. Grazú V, Moros M, Sánchez-Espinel C. Nanocarriers as nanomedicines: design concepts and recent advances. In: de la Fuente JM, Grazú V, editors. Nanobiotechnology: Inorganic Nanoparticles vs Organic Nanoparticles. Oxford: Elsevier; 2012:337-440.

66. Mu Q, Jiang G, Chen L, et al. Chemical basis of interactions between engineered nanoparticles and biological systems. Chem Rev. 2014;114:7740-7781.

67. Nel AE, Mädler L, Velegol D, et al. Understanding biophysicochemical interactions at the nano-bio interface. Nat Mater. 2009;8:543-557.

68. Zhang XQ, Xu X, Bertrand N, Pridgen E, Swami A, Farokhzad OC. Interactions of nanomaterials and biological systems: implications to personalized medicine. Adv Drug Deliv Rev. 2012;64:1363-1384.
69. Song G, Petschauer JS, Madden AJ, Zamboni WC. Nanoparticles and the mononuclear phagocyte system: pharmacokinetics and applications for inflammatory diseases. Curr Rheumatol Rev. 2014;10: 22-34.

70. Sanhai WR, Sakamoto JH, Canady R, Ferrari M. Seven challenges for nanomedicine. Nat Nanotechnol. 2008;3:242-244.

71. Duncan R, Vicent MJ. Polymer therapeutics-prospects for 21 st century: the end of the beginning. Adv Drug Deliv Rev. 2013;65:60-70.

72. Salmaso S, Caliceti P. Stealth properties to improve therapeutic efficacy of drug nanocarriers. J Drug Deliv. 2013;2013:374252.

73. Kannan RM, Nance E, Kannan S, Tomalia DA. Emerging concepts in dendrimer-based nanomedicine: from design principles to clinical applications. J Intern Med. 2014;276:579-617.

74. Oberdörster G. Safety assessment for nanotechnology and nanomedicine: concepts of nanotoxicology. J Intern Med. 2010;267:89-105.

75. Pelaz B, Charron G, Pfeiffer C, et al. Interfacing engineered nanoparticles with biological systems: anticipating adverse nano-bio interactions. Small. 2013;9:1573-1584.

76. Lammers T, Hennink WE, Storm G. Tumour-targeted nanomedicines: principles and practice. Br J Cancer. 2008;99:392-397.

77. Choi CH, Alabi CA, Webster P, Davis ME. Mechanism of active targeting in solid tumors with transferring-containing gold nanoparticles. Proc Natl Acad Sci U S A. 2010;107:1235-1240.

78. Katsogiannou M, Peng L, Catapano CV, Rocchi P. Active-targeted nanotherapy strategies for prostate cancer. Curr Cancer Drug Targets. 2011;11: 954-965.

79. Khanna VK. Targeted delivery of nanomedicines. ISRN Pharmacol. 2012;2012:571394.

80. Luo D, Carter KA, Lovell JF. Nanomedical engineering: shaping future nanomedicines. Wiley Interdiscip Rev Nanomed Nanobiotechnol. 2015;7:169-188.

81. Lembo D, Cavalli R. Nanoparticulate delivery systems for antiviral drugs. Antivir Chem Chemother. 2010;21:53-70.

82. Bhaskar S, Tian F, Stoeger T, et al. Multifunctional nanocarriers for diagnostics, drug delivery and targeted treatment across blood-brain barrier: perspectives on tracking and neuroimaging. Part Fibre Toxicol. 2010;7:3.

83. Khanbabaie R, Jahanshahi M. Revolutionary impact of nanodrug delivery on neuroscience. Curr Neuropharmacol. 2012;10:370-392.

84. Micheli MR, Bova R, Magini A, Polidoro M, Emiliani C. Lipid-based nanocarriers for CNS-targeted drug delivery. Recent Pat CNS Drug Discov. 2012;7:71-86.

85. Alyautdin R, Khalin I, Nafeeza MI, Haron MH, Kuznetsov D. Nanoscale drug delivery systems and the blood-brain barrier. Int J Nanomedicine. 2014;9:795-811.

86. Jain KK. Nanodiagnostics: application of nanotechnology in molecular diagnostics. Expert Rev Mol Diagn. 2003;3:153-161.

87. Azzazy HM, Mansour MM, Kazmierczak SC. Nanodiagnostics: a new frontier for clinical laboratory medicine. Clin Chem. 2006;52: 1238-1246.

88. Baptista PV. Nanodiagnostics: leaving the research lab to enter the clinics? Diagnosis. 2014;1:305-309.

89. Boulaiz H, Alvarez PJ, Ramirez A, et al. Nanomedicine: application areas and development prospects. Int J Mol Sci. 2011;12:3303-3321.

90. Wong IY, Bhatia SN, Toner M. Nanotechnology: emerging tools for biology and medicine. Genes Dev. 2013;27:2397-2408.

91. Jain KK. Role of nanodiagnostics in personalized cancer therapy. Clin Lab Med. 2012;32:15-31.

92. Tavallaie R, De Almeida SR, Gooding JJ. Toward biosensors for the detection of circulating microRNA as a cancer biomarker: an overview of the challenges and successes. Wiley Interdiscip Rev Nanomed Nanobiotechnol. 2015;7:580-592.

93. Brambilla D, Le Droumaguet B, Nicolas J, et al. Nanotechnologies for Alzheimer's disease: diagnosis, therapy, and safety issues. Nanomedicine. 2011;7:521-540.

94. DiSanto RM, Subramanian V, Gu Z. Recent advances in nanotechnology for diabetes treatment. Wiley Interdiscip Rev Nanomed Nanobiotechnol. 2015;7:548-564. 
95. Veiseh O, Tang BC, Whitehead KA, Anderson DG, Langer R. Managing diabetes with nanomedicine: challenges and opportunities. Nat Rev Drug Discov. 2015;14:45-57.

96. Wang S, Inci F, De Libero G, Singhal A, Demirci U. Point-ofcare assays for tuberculosis: role of nanotechnology/microfluidics. Biotechnol Adv. 2013;31:438-449.

97. Salieb-Beugelaar GB, Hunziker PR. Towards nano-diagnostics for rapid diagnosis of infectious diseases - current technological state. Eur J Nanomed. 2014;6:11-28.

98. Salieb-Beugelaar GB, Hunziker PR. Towards nano-diagnostics for bacterial infections. Eur J Nanomed. 2015;7:37-50.

99. Bawa R, Johnson S. The ethical dimensions of nanomedicine. Med Clin North Am. 2007;91:881-887.

100. Sweeney AE, Seal S, Vaidyanathan P. The promises and perils of nanoscience and nanotechnology: exploring emerging social and ethical issues. Bull Sci Technol Soc. 2003;23:236-245.

101. Sweeney AE. Social and ethical dimensions of nanoscale science and engineering research. Sci Eng Ethics. 2006;12:435-464.

102. Allhoff F. The coming era of nanomedicine. Am J Bioeth. 2009;9: 3-11.

103. Foladori G, Invernizzi N. Nanotechnology for the poor? PLoS Med. 2005;2:e280.

104. Maclurcan D. Nanotechnology and Global Equality. Singapore: Pan Stanford Publishing Pte. Ltd; 2012.

105. Hall RM, Sun T, Ferrari M. A portrait of nanomedicine and its bioethical implications. J Law Med Ethics. 2012;40:763-769.

106. Khushf G, Siegel RA. What is unique about nanomedicine? The significance of the mesoscale. J Law Med Ethics. 2012;40:780-794.

107. Dresser R. Building an ethical foundation for first-in-human nanotrials. J Law Med Ethics. 2012;40:802-808.

108. Hogle LF. Concepts of risk in nanomedicine research. J Law Med Ethics. 2012;40:809-822.

109. King NM. Nanomedicine first-in-human research: challenges for informed consent. J Law Med Ethics. 2012;40:823-830.

110. Kimmelman J. Beyond human subjects: risk, ethics, and clinical development of nanomedicines. J Law Med Ethics. 2012;40:841-847.

111. Resnik DB. Responsible conduct in nanomedicine research: environmental concerns beyond the common rule. J Law Med Ethics. 2012;40:848-855.

112. Kuiken T. Nanomedicine and ethics: is there anything new or unique? Wiley Interdiscip Rev Nanomed Nanobiotechnol. 2011;3:111-118.

113. Beauchamp TL, Childress JF. Principles of Biomedical Ethics. 6th ed. New York: Oxford University Press; 2009.

114. Resnik DB, Tinkle SS. Ethical issues in clinical trials involving nanomedicine. Contemp Clin Trials. 2007;28:433-441.

115. Hope T, Fulford KW. The Oxford Practice Skills Project: teaching ethics, law and communication skills to clinical medical students. $J$ Med Ethics. 1994;20:229-234

116. LeBlanc TW. Communication skills training in the twenty-first century. AMA J Ethics. 2015;17:140-143.

117. Arnold RM, Forrow L, Wartman SA, Teno J. Teaching clinical medical ethics: a model programme for primary care residency. J Med Ethics. 1988;14:91-96.

118. Eichna LW. Medical-school education, 1975-1979: a student's perspective. N Engl J Med. 1980;303:727-734.

119. $\mathrm{MD} / \mathrm{PhD}$ in Medicine and Nanoscale Science or Engineering [webpage on the Internet]. Albany: Colleges of Nanoscale Science + Engineering, SUNY Polytechnic Institute. Available from: http://www.sunycnse. com/PioneeringAcademics/GraduatePrograms/Nanomedicine.aspx. Accessed August 12, 2015.

120. MD-PhD program [webpage on the Internet]. Bryan: Texas A\&M Health Science Center. Available from: https://medicine.tamhsc.edu/ md-phd/index.html. Accessed August 12, 2015.

121. Scholarly Concentrations Program [webpage on the Internet]. Houston: The University of Texas Health Science Center at Houston. Available from: https://med.uth.edu/oep/medical-education/student-programs/ scholarly-concentrations-program/. Accessed August 12, 2015.
122. Areas of Concentration [webpage on the Internet]. New York: Weill Cornell Medical College. Available from: http://weill.cornell.edu/ education/curriculum/aoc.html. Accessed August 12, 2015.

123. Vélez JM, Vélez JJ. The eminent need for an academic program in universities to teach nanomedicine. Int $J$ Nanomedicine. 2011;6:1733-1738.

124. Weatherall D. Science and medical education: is it time to revisit Flexner? Med Educ. 2011;45:44-50.

125. Spencer AL, Brosenitsch T, Levine AS, Kanter SL. Back to the basic sciences: an innovative approach to teaching senior medical students how best to integrate basic science and clinical medicine. Acad Med. 2008;83:662-669.

126. Brauer DG, Ferguson KJ. The integrated curriculum in medical education: AMEE Guide No 96. Med Teach. 2015;37:312-322.

127. Lammers T, Aime S, Hennink WE, Storm G, Kiessling F. Theranostic nanomedicine. Acc Chem Res. 2011;44:1029-1038.

128. Rajeeva BB, Menz R, Zheng Y. Towards rational design of multifunctional theranostic nanoparticles: what barriers do we need to overcome? Nanomedicine (Lond). 2014;9:1767-1770

129. Taking the MCAT $^{\circledR}$ Exam [webpage on the Internet]. Washington: Association of American Medical Colleges. Available from: https://www. aamc.org/students/applying/mcat/about/. Accessed August 24, 2015.

130. Kies S, Shultz M. Proposed changes to the United States Medical Licensing Examination: impact on curricula and libraries. J Med Libr Assoc. 2010;98:12-16.

131. Haist $\mathrm{S}$. The changing United States Medical Licensing Examination. SGIM Forum. 2013;36(1):9,11.

132. Haist SA, Katsufrakis PJ, Dillon GF. The evolution of the United States Medical Licensing Examination (USMLE): enhancing assessment of practice-related competencies. JAMA. 2013;310:2245-2246.

133. Barbieri JS. Basic science content in the USMLE Step 1. JAMA. 2014;311:1358-1359.

134. What's on the MCAT Exam? [webpage on the Internet]. Washington: Association of American Medical Colleges; 2015. Available from: https://students-residents.aamc.org/applying-medical-school/article/ whats-mcat-exam/. Accessed November 25, 2015.

135. United States Medical Licensing Examination (USMLE). Changes to USMLE ${ }^{\circledR}$ 2015-2016. USMLE; 2015. Available from: http:// www.usmle.org/pdfs/Changes_to_USMLE_handout.pdf. Accessed August 19, 2015.

136. United States Medical Licensing Examination (USMLE). USMLE Step 1: Content Description and General Information. Federation of State Medical Boards of the United States, Inc. (FSMB), National Board of Medical Examiners ${ }^{\circledR}\left(\mathrm{NBME}^{\circledR}\right)$; 2015. Available from: http://www.usmle.org/pdfs/step-1/2015content_step1.pdf. Accessed August 19, 2015.

137. United States Medical Licensing Examination (USMLE). USMLE Step 2: Clinical Knowledge (CK): Content Description and General Information. Federation of State Medical Boards of the United States, Inc. (FSMB), National Board of Medical Examiners ${ }^{\circledR}\left(\mathrm{NBME}^{\circledR}\right)$; 2015. Available from: http://www.usmle.org/pdfs/step-2-ck/2015_ Step2CK_Content.pdf. Accessed August 19, 2015.

138. Kanter SL. The future of academic medicine: what can Academic Medicine do about it? Acad Med. 2009;84:405-406.

139. Eisenstein M. Artificial organs: Honey, I shrunk the lungs. Nature. 2015;519:S16-S18.

140. Schmidt HG, Norman GR, Boshuizen HP. A cognitive perspective on medical expertise: theory and implication. Acad Med. 1990;65:611-621.

141. Eva KW. What every teacher needs to know about clinical reasoning. Med Educ. 2005;39:98-106.

142. Bowen JL. Educational strategies to promote clinical diagnostic reasoning. N Engl J Med. 2006;355:2217-2225.

143. Custers EJ. Thirty years of illness scripts: theoretical origins and practical applications. Med Teach. 2015;37:457-462.

144. Cavazos LF. Restructuring education and its impact on medical education. Acad Med. 1990;65:230-233. 
145. Kanter SL. Toward a sound philosophy of premedical education. Acad Med. 2008;83:423-424.

146. Sweeney AE, Vaidyanathan P, Seal S. Undergraduate research and education in nanotechnology. The International Journal of Engineering Education. 2006;22:157-170.

147. Balser JR, Baruchin A. Science at the interstices: an evolution in the academy. Acad Med. 2008;83:827-831.
148. Kuhn TS. The Structure of Scientific Revolutions. 2nd ed. Chicago: University of Chicago Press; 1970.

149. Baillie J. The structure of medical revolutions. Cogito. 1988;2: $27-29$.

\section{Publish your work in this journal}

The International Journal of Nanomedicine is an international, peerreviewed journal focusing on the application of nanotechnology in diagnostics, therapeutics, and drug delivery systems throughout the biomedical field. This journal is indexed on PubMed Central, MedLine, CAS, SciSearch ${ }^{\circledR}$, Current Contents ${ } /$ Clinical Medicine,
Journal Citation Reports/Science Edition, EMBase, Scopus and the Elsevier Bibliographic databases. The manuscript management system is completely online and includes a very quick and fair peer-review system, which is all easy to use. Visit http://www.dovepress.com/ testimonials.php to read real quotes from published authors.

Submit your manuscript here: http://www.dovepress.com/international-journal-of-nanomedicine-journal 